\title{
FATORES HUMANOS QUE INTERFEREM NA \\ JORNADA DE TRABALHO
}

\section{Thaylane de Almeida Sérgio da Silva}

Centro Universitário de Volta Redonda (UNIFOA)

Mestranda em enfermagem

E-mail: thaylanealmeida@yahoo.com.br

\section{Jocélio de Souza Maciel}

Fisioterapeuta graduado no Centro Universitário de Barra Mansa, UBM Mestre em Gestão e Estratégia de negócios

Docente o Curso de Fisioterapia no Centro Universitário de Barra Mansa, UBM.

E-mail: Jocélio.Maciuel@ubm.br 


\section{Resumo}

Este estudo estabelece como objetivo geral identificar fatores humanos que interferem na jornada de trabalho. A monotonia, fadiga e motivação são três aspectos muito importantes que obrigatoriamente devem ser observados em atividades de análise do trabalho humano. A monotonia e fadiga estão presentes em todos os trabalhos e, se não podem ser totalmente eliminadas, podem ser controladas tornando o ambiente de trabalho mais interessante e motivador. Foram utilizadas como fontes de informações publicações sobre a temática encontradas em livros, periódicos e sites científicos, de 1995 a 2012; identificando, neste período, as publicações em que "vigilância em saúde" e "saúde do trabalhador" fossem os temas principais. Este estudo, de natureza qualitativa, caracteriza-se como bibliográfico, descritivo e exploratório. O estudo enfatizou a importância do enfermeiro do trabalho junto ao trabalhador para identificar os possíveis sinais de agravos a saúde decorrente da jornada de trabalho, ressaltando ainda ser necessária uma mudança na forma de pensamento de determinados empregadores, quanto às questões referentes à prevenção, uma vez que esse fator associa-se diretamente à melhoria da qualidade de vida dos trabalhadores. Em suma, quanto maior o investimento em qualidade de vida, maior será o retorno em termos de produtividade e qualidade, afetando de forma direta e positiva a saúde financeira da empresa.

Palavras chave: Jornada de trabalho. Fatores humanos. Qualidade de vida.

\section{Abstract}

This study establishes a general methodology of functions that interfere in the working day. The monotony, fatigue and animation are the most important aspects that the obligation to be observed in activities of analysis of human work. Monotony and fatigue are present in every job and, can not be totally eliminated, can be taken in the most interesting and motivating work environment. Sources of information on the publication of books, periodicals and scientific sites were searched from 1995 to 2012; identifying, in this period, the publications in which "health surveillance" and "worker health" were the main themes. This qualitative study serves as a source of information, descriptive and to be used as a source of information. The way to assign the data, when the questions are interposed, since this is associated to the improvement of the workers' quality of life. In short, the greatest commitment to quality of life will be the return in terms of productivity and quality, affecting the company's financial health in a direct and positive way.

Keywords: Working day. Human factors. Quality of life. 


\section{Introdução}

O trabalho, no decorrer da história, foi ocupando a maior parte do tempo do ser humano. $\mathrm{O}$ que de início era para suprir suas necessidades básicas de subsistência, passa a ser, principalmente após a Revolução Industrial, o ponto central da vida do homem.

O homem, dessa forma, passa maior parte de sua vida em seus locais de trabalho, dedicando sua força, energia e esforços para as organizações, ou seja, disponibilizando maior parte do seu tempo ao trabalho do que propriamente com suas famílias e amigos.

No Brasil, a jornada de trabalho é regulamentada pela Constituição Federal em seu art. $7^{\circ}$ XIII e a CLT art. 58, não pode ultrapassar 8 horas diárias (salvo exceção que veremos a diante): "Art. $4^{\circ}$ Considera-se como de serviço efetivo o período em que o empregado esteja à disposição do empregador, aguardando ou executando suas ordens, salvo disposição especial expressamente consignada." É, também, considerado como jornada o período em que o empregado está à disposição do empregador, mesmo que em sua residência (Wikipedia, 2008).

A doutrina distingue jornada de trabalho e horário de trabalho. Aquela é o tempo em que o empregado esteja à disposição de seu empregador aguardando ou executando ordens, este inclui o intervalo entre a jornada para repouso e alimentação. Portanto, o horário representa os marcos de início e fim de um dia de trabalho, mas na jornada só se computa o efetivo tempo de trabalho.

A jornada semanal de 48 horas de trabalho foi estabelecida no Brasil em 1943, por meio da Consolidação das Leis do Trabalho (CLT) de 1943.

Em 1988, essa jornada foi reduzida á 44 horas, pela Constituição Federal de 1988 (vide Indicador Normativo 4 - Duração máxima do trabalho).

Em 1998, foi aprovada a Lei 9.601 de 1998, que estabelece um "banco de horas", um sistema de compensação de horas extras mais flexível, que possibilita à empresa adequar a jornada de trabalho dos empregados às suas necessidades de produção, mediante convenção ou acordo coletivo de trabalho. Em momentos de grande atividade da empresa, a jornada de trabalho pode ser ampliada (a um máximo de duas horas extras por dia), durante um determinado período, sem que essas horas sejam remuneradas, mas sim compensadas posteriormente em momentos de retração da produção, por meio de folgas ou de redução da jornada diária, até a "quitação" das horas excedentes (Organização Internacional do Trabalho - OIT, 2009).

Segundo os dados da Pesquisa Nacional para Amostra de Domicílios (PNAD), em 2007, 35,5\% dos ocupados trabalharam uma jornada superior às 44 horas semanais e $20,3 \%$ trabalharam uma jornada superior às 48 horas semanais. Isso significa que uma porcentagem importante dos trabalhadores no Brasil 
executa jornadas semanais longas, ou seja, superiores ao limite legal, ainda que essa porcentagem seja significativamente inferior à registrada em 1992, quando $43,3 \%$ dos ocupados trabalharam mais de 44 horas semanais e $25,7 \%$ mais de 48 horas semanais (Organização Internacional do Trabalho - OIT, 2009).

A carga excessiva de horas de trabalho afeta mais os homens que as mulheres. Em 2007, 25,2\% das mulheres e 43,2\% dos homens trabalharam mais de 44 horas semanais. Da mesma forma, 13,7\% das mulheres e 25,2\% dos homens trabalharam mais de 48 horas semanais. A jornada média semanal de trabalho das mulheres foi de 36,4 horas e a dos homens 44,4 (Organização Internacional do Trabalho - OIT, 2009).

O objeto do presente estudo é identificar fatores humanos que interferem na jornada de trabalho.

A monotonia, fadiga e motivação são três aspectos muito importantes que devem interessar a todos aqueles que realizam análise e projeto do trabalho humano. A monotonia e fadiga estão presentes em todos os trabalhos e, se não podem ser totalmente eliminados, podem ser controlados e substituídos por ambientes mais interessantes e motivadores. Sendo assim, o objetivo proposto para o estudo é descrever os fatores decorrentes da jornada de trabalho que afetam qualidade de vida do trabalhador.

Problematização do estudo é: Quais os fatores do ambiente de trabalho que, se modificados, melhorariam a qualidade de vida dos empregados?

Dentre os fatores estão: iluminação, treinamentos, adaptação do trabalhador, utilização correta das cadeiras ergonômicas disponíveis no setor, assim como uma participação efetiva e correta de todos no programa de ginástica laboral, adequação de algumas bancadas de trabalho às características antropométricas do trabalhador, e, finalmente, como uma ação mais abrangente, a redução da jornada de trabalho do $2^{\underline{0}}$ e do $3^{\circ}$ turno para 6 horas diárias.

A questão da idade, sexo e deficiências físicas no trabalho é um assunto da atualidade, que está atraindo, cada vez mais, a atenção dos pesquisadores. Até agora, o homem adulto de 20 a 30 anos tem sido usado, quase sempre, como paradgma do trabalhador, mas isso está sendo cada vez menos real, à medida que outros segmentos da sociedade estão participando, cada vez mais das atividades produtivas.

Dessa forma, a organização passa a se preocupar em oferecer um ambiente que traga ao indivíduo: conforto, respeito, segurança e bem-estar, entre outros. Ou seja, a organização deve oferecer um ambiente propício e que favoreça o uso de suas capacidades.

Enquanto acadêmica do curso de especialização, foi possível perceber a importância do papel do enfermeiro do trabalho nos setores, podendo 
identificar possíveis riscos relacionados a jornada de trabalho e os fatores humanos referentes a mesma , mostrando a incessante luta do trabalhador para conseguir meios que facilitassem suas tarefas diárias e transformassem algo prazeroso e que melhore sua qualidade de vida.

Metodologia

O estudo se caracteriza como descritivo e exploratório de natureza qualitativa.

A pesquisa bibliográfica é desenvolvida com base em material já elaborado, constituído principalmente de livros e artigos científicos. Embora em quase todos os estudos seja exigido algum tipo de trabalho dessa natureza, há pesquisas desenvolvidas exclusivamente a partir de fontes bibliográficas. Boa parte dos estudos exploratórios pode ser definida como pesquisa bibliográfica (GIL 4 ed. ,2002).

De acordo com Goldenbergos (1998), métodos qualitativos enfatizam as particularidades de um fenômeno em termos de seu significado para o grupo pesquisado.

Os dados qualitativos consistem em descrições detalhadas de situações com o objetivo de compreender os indivíduos em seus próprios termos, obrigando o pesquisador a ter flexibilidade e criatividade no momento de coletar e analisar esses dados.

Foram utilizadas, como fontes de informações, as publicações sobre a temática encontrada em livros científicos, revistas, periódicos e sites científicos, nos anos de 1995 a 2012, identificando-se, neste período, reflexões sobre a pauta vigilância em saúde e saúde do trabalhador.

Foram utilizados como descritores, identificados nos títulos dos artigos, os termos: Jornada de trabalho, enfermeiro do trabalho, Fatores humanos, prevenção e promoção à saúde do trabalhador.

Os resumos dos artigos que atendiam aos critérios de inclusão foram selecionados e lidos integralmente.

Após repetidas leituras dos artigos, foram identificadas as categorias previamente definidas: caracterização dos autores, conceitos, jornada de trabalho, fatores humanos.

\section{Fundamentação Teórica}

\section{Ritmos circadianos}

O organismo humano apresenta oscilações com quase todas as suas funções fisiológicas com um ciclo aproximado de 24 horas. Daí o nome de circadiano que, em latim, circa dies, significa cerca de um dia. 
Os ritmos circadianos estão presentes em diversas funções corpóreas como, por exemplo: temperatura corporal, corticosteróides e eletrólitos do soro e urinários, funções cardiovasculares, secreção de enzimas gástricas, número de leucócitos do sangue, força muscular, estado de alerta, humor, memória imediata e a longo prazo.

Indivíduos matutinos e vespertinos - Os estudos sobre os Ritmos Circadianos demonstram que há grandes variações individuais e que é possível distinguir pelo menos dois tipos diferentes entre si: os matutinos e vespertinos.

Os matutinos são aqueles que acordam de manhã com mais facilidade, apresentam melhor disposição na parte da manhã e costumam dormir cedo. A sua temperatura sobe mais rapidamente, a partir das 6 horas e atinge o máximo por volta das 12 horas.

Os vespertinos são mais ativos à tarde e no inicio da noite. A temperatura corporal sobe mais lentamente na parte da manhã e aquela máxima só ocorre por volta das 18 horas. Encontram menor disposição na parte da manhã, mas, em compensação, são mais facilmente adaptáveis ao trabalho noturno.

Em uma população, os casos extremos de indivíduos tipicamente matutinos ou vespertinos constituem a minoria. A maioria distribui-se em posições intermediárias, com diversos graus de tendências entre esses dois extremos.

A organização temporal do trabalho em turnos traz inegáveis prejuízos para a saúde do trabalhador, tanto no aspecto físico, como psíquico, emocional e social, sendo alguns bastante conhecidos e outros, ainda, necessitando de maior investigação. Tarefas que resultam em esforços adicionais, em virtude da organização do trabalho, deixam marcas indeléveis no trabalhador, como as manifestações psicossomáticas.

O trabalho em turnos e o noturno, ao provocar redução do estado de vigília, afeta a produtividade e a segurança, pode também ser causa de uma série de distúrbios, pois 30\% dos trabalhadores de turnos se queixam de sintomas de gastrite e das doenças cardiovasculares relacionadas com trabalho, 7\% delas são atribuídas ao trabalho em turnos oun noturno, havendo, também, uma conexão entre pertubação do sono e hipertensão arterial em trabalhadores noturnos, colocando os mesmos sob risco de doença coronariana. (FILHO, p 70 e 71. 2002).

Por isso é de grande Importância pra o enfermeiro do trabalho identificar as possíveis morbidades que os trabalhadores possam apresentar.

\section{Início da atividade}


Da mesma forma que máquinas térmicas, como os automóveis, precisam ser pré-aquecidos para entrar em funcionamento de "regime", o corpo humano também passa por diversas transformações fisiológicas no início da atividade, especialmente aquelas que exigem esforço físico pesado.

Portanto, para um trabalho físico pesado, é aconselhável fazer um préaquecimento de 2 a 3 minutos, ou iniciar a atividade com menor intensidade, dando uma oportunidade para o organismo ir adaptando-se, de modo que não haja um grande desbalanceamento entre a oferta e a demanda de oxigênio

Em algumas empresas, adota-se a prática de ginástica de aquecimento, antes da jornada de trabalho, assim como os atletas fazem aquecimento muscular antes das competições.

\section{Adaptação pelo treinamento}

Uma pessoa que realiza uma tarefa pela primeira vez, provavelmente sentirá mais dificuldade que outra que já esteja acostumada a esse trabalho. Essa pessoa vai fazer movimentos bruscos, deselegantes, cometer mais erros e se sentir mais fadigada.

No dia seguinte, já sentirá menos dificuldades. Com o tempo, a sua coordenação muscular vai melhorando e os seus movimentos se tornam mais suaves e harmoniosos. Em consequência, o consumo de energia reduz-se, a fadiga diminui e a sua produtividade aumenta.

\section{Substâncias estimulantes}

Diversas substâncias estimulantes costumam ser usadas pelos trabalhadores para quebrar a monotonia e manter a atenção.

$\checkmark$ Cafeína: Tem sido apontada como estimulante quando ingerida em doses moderadas. Serve para aumentar a vigilância, reduzir a inibição, aliviar a fadiga e provocar queda do apetite.

$\checkmark$ Fumo: Reduz a capacidade respiratória e é utilizado por quem depende de capacidade motora.

$\checkmark$ Álcool: A pessoa fica mais desinibida, motivada, porém pode prejudicar o desempenho, acarretar perda de memória e apetite.

\section{Monotonia}

Um ambiente uniforme, pobre em estímulos ou com pouca variação das excitações configura a reação do organismo à monotonia. Os sintomas mais indicativos da monotonia são uma sensação de fadiga, sonolência, aumento do 
tempo de reação, morosidade e uma diminuição da atenção. As operações repetitivas na indústria e o tráfego rotineiro são condições propícias à monotonia, cujas possíveis causas são:

$\checkmark$ Atividades com baixa frequência de excitação e de grande exigência de atenção continuada;

$\checkmark$ Ambientes com isolamento social, pouco contato com colegas de trabalho;

$\checkmark$ Atividades prolongadas e repetitivas de pouca dificuldade;

$\checkmark$ Curta duração do ciclo de trabalho;

$\checkmark$ Locais com restrição dos movimentos corporais;

$\checkmark$ Períodos curtos de aprendizagem.

Reforçando essas descrições anteriores, LEPLAT e CUNY (1977) afirmam que os fatores da monotonia provocam uma automatização dos comportamentos, com graves inconvenientes quando o trabalho se apresenta de forma rotineira e repetitiva. A monotonia faz com que a informação não seja registrada no campo de trabalho, senão em determinados momentos privilegiados do ciclo.

Os órgãos dos sentidos são os mais sensíveis às mudanças nas excitações permanentes de nível constante. As variações de excitação estimulam as estruturas de ativação do cérebro, e excitações constantes não transmitem sinais aos órgãos que provocam ativação. Assim, dentro do sistema sensorial, as excitações constantes e regulares podem se comportar como se não houvesse novas excitações, porque o organismo se adapta ao nível das excitações constantes e só seria ativado novamente com a mudança de nível dessa excitação. É importante destacar que as tarefas repetitivas tendem a diminuir o nível de excitação do cérebro, refletindo-se numa diminuição geral das reações do organismo. As variações individuais a este estado de monotonia ocorrem quando:

$\checkmark$ Os indivíduos que têm outros objetivos na vida se mostram mais resistentes à monotonia, fazendo do seu trabalho repetitivo apenas um meio para alcançar esses objetivos;

$\checkmark$ Os aprendizes, para os quais o trabalho ainda tem sabor de novidade, apresentam menos sintomas de monotonia que os trabalhadores experientes;

$\checkmark$ As pessoas de caráter mais extrovertido apresentam maiores riscos de monotonia.

A repetição nos postos de trabalho dos indivíduos provoca insatisfação, aborrecimento e desânimo e caracteriza-se por um grande desestímulo ao processo de criatividade, acentuado por um elevado grau de absenteísmo. 
Em termos operacionais, existem duas consequências mensuráveis da monotonia:

$\checkmark$ A diminuição da atenção

$\checkmark$ Aumento do tempo de reação

No entanto, uma das consequências mais sérias da monotonia é a saturação psíquica: um conflito interior entre o "dever de trabalhar" e um forte desejo de "parar de trabalhar". Esse conflito provoca ansiedade e tensões cada vez mais fortes nas pessoas submetidas a um ritmo de trabalho repetitivo (RODRIGUES, 1999).

\section{Fadiga no trabalho}

Fadiga é o efeito de um trabalho continuado, que provoca uma redução reversível da capacidade do organismo e uma degradação qualitativa desse trabalho.

O trabalho como meio para ganho do sustento apresenta-se de diversas formas. Há pessoas que passam uma vida inteira de trabalho realizando atividades pesadas que demandam muito esforço físico e pouco desgaste mental.

A fadiga é característica de alguns tipos de trabalho como os que ocorrem monotonia, falta de motivação para trabalhar, sobrecarga de tarefa, aumento da informatização, novos processos industriais que, muitas vezes, levam as pessoas a permanecerem por longos períodos em posições quase estáticas frente aos postos de trabalho, desempenhando tarefas mecânicas e repetitivas (PEREIRA, 2009)

Outros tipos de trabalho são considerados leves, porém muito repetitivos, causando muitas vezes o mesmo desgaste físico de um trabalho pesado. Entretanto o que chama a atenção para este estudo é que hoje, mesmo com tanto avanço tecnológico, o trabalho físico fatigante ainda existe. Esse tipo de trabalho é encontrado em grande parte nos países subdesenvolvidos, países em que a mão de obra é considerada barata, a procura por emprego é grande e o nível de instrução é baixo, sendo essas algumas das características mais comuns encontradas nesses países (RODRIGUES, 1999).

De fato, a sobrecarga de trabalho é apontada na literatura como uma das principais fontes de estresse. A dupla jornada aumenta a carga psíquica e pode contribuir para a ocorrência de acidentes de trabalho e problemas na vida familiar. As consequências, relatadas pelas participantes, correspondem a estudos já amplamente divulgados que reconhecem a privação de sono como um estressor que intensifica mudanças de humor, irritabilidade e dificuldade de concentração (LOURENÇÃO, 2010). 


\section{Tipos de fadiga no trabalho}

Cada atividade laboral desempenha uma função fisiológica no organismo do trabalhador, podendo desenvolver momentos de cansaço denominados de fadiga, sendo essa física ou cognitiva. Segundo GRANDJEAN (1998, p.137) “com a palavra fadiga designamos um estado que todos conhecemos na rotina diária. Em regra geral, relaciona-se esta palavra com uma capacidade de produção diminuída e uma perda de motivação para qualquer atividade"

A realização de trabalho, fisiologicamente tem como consequência o desgaste. Esse desgaste pode acometer alguns órgãos do organismo humano de diversas formas. Através de um determinado grau de esforço seja mental ou físico, a fadiga acaba surgindo. As formas mais comuns são:

$\checkmark$ A fadiga gerada pela exigência do aparelho visual (fadiga visual);

$\checkmark$ A fadiga provocada pela exigência física de todo o organismo (fadiga corporal geral);

$\checkmark$ A fadiga do trabalho mental (fadiga mental);

$\checkmark$ A fadiga produzida pela exigência exclusiva das funções psicomotoras (fadiga da destreza ou nervosa);

$\checkmark$ Aquela gerada pela monotonia do trabalho ou do ambiente;

$\checkmark$ O somatório das influências fatigantes prolongadas (fadiga crônica);

$\checkmark$ A fadiga circadiana ou nictemérica gerada pelo ritmo biológico do ciclo de dia-noite que se instala periodicamente e conduz ao sono.

Todas as formas de fadiga descritas acima são determinadas por situações geradoras de estresse, essas situações podem provir de esforços leves, porém, contínuos ou de um grande esforço breve que diminui o potencial para os diversos tipos de trabalho. Essa situação é determinada como grau de fadiga.

Para exercícios em que há um esforço submáximo, ocorre uma redução significativa no glicogênio muscular que está relacionada à fadiga observada no exercício submáximo prolongado. Essa fadiga por carência de nutrientes ocorre até mesmo quando se dispõe de oxigênio suficiente para gerar energia através das vias aeróbias. Esse tipo de fadiga ocorre normalmente com atletas de performance e com trabalhadores que estão expostos a atividades semelhantes no que tange o desgaste físico. Exemplo deste é encontrado nas tarefas de descarga manual de caminhão, quando o trabalhador tende a aplicar muita força, trabalhando com o máximo ou submáximo de sua capacidade de força para realizar uma tarefa dentro de um ritmo pré-determinado. A tendência para eliminação do esforço físico convive com a necessidade maior de produção e a eficácia, o que resultou num ritmo acelerado na maioria das operações industriais. 
Para situações de trabalho, um indivíduo estará executando uma atividade física muito leve ou leve quando estiver usando até $25 \%$ de sua capacidade aeróbia; moderadamente pesada, de 25 a 37,5\% de sua capacidade aeróbia; pesada, de 37,5 a 50\%; pesadíssima, de 50 a 62,5\%; extremamente pesada, acima de $62,5 \%$ de sua capacidade aeróbia.

Esses limiares aeróbios determinam um possível grau de desgaste físico que está relacionado ao surgimento da fadiga.

A fadiga muscular ocorre de forma pontificada e apresenta um quadro doloroso agudo, levando à dor, enquanto a fadiga generalizada não acompanha um ponto específico doloroso; a dor é dispersa de forma geral no organismo o que leva a pessoa a sentir-se cansada, desmotivada para realização de qualquer tipo de tarefa, sendo que, para cada tipo de fadiga, ocorre um processo fisiológico diferente.

\section{Formas de fadiga e métodos para identificação no trabalho.}

Existem várias formas pelas quais se podem identificar fadiga em indivíduos expostos à realização de trabalho, tanto para trabalhos físicos no campo do esporte como no trabalho em indústrias.

No trabalho físico- realizado dentro das empresas, nos setores de produção- outro tipo de fadiga ocorre com mais frequência, é a fadiga muscular. Estudos demonstram que a fadiga muscular aumenta em proporção quase direta com a intensidade de depleção do glicogênio muscular, ou seja, quanto maior o tempo de uma contração muscular, menor será a quantidade de nutrientes para suprir a necessidade de contração do músculo, levando à fadiga. Portanto, as realizações de trabalhos musculares repetitivos, dinâmicos ou estáticos podem acarretar fadiga precoce, proveniente desse déficit de nutrientes.

Verifica-se a ocorrência de fadiga ocupacional, considerando os desgastes das capacidades físicas e mentais, uma vez que a docência predispõe o trabalhador a fatores que estão interligados. Sendo assim, a fadiga é exposta como um dos agravos decorrentes de atividades laborais. A mesma é caracterizada como um fenômeno multidimensional que compreende aspectos fisiológicos e psicológicos e está relacionada à sensação de cansaço, falta de energia e exaustão, que resultam na diminuição da capacidade de realizar atividades cotidianas. Além disso, a fadiga altera o estado de alerta e vigília, assim como a motivação. ( Nery, 2013)

Acredita-se numa série de ações que possam auxiliar na prevenção da fadiga. O trabalho de conscientização de todos, incluindo chefias diretas, para que os trabalhadores alternem períodos de trabalho sentado e em pé a cada 20 ou 
30 min., possibilitando a utilização correta das cadeiras ergonômicas disponíveis no setor, assim como uma participação efetiva e correta de todos no programa de ginástica laboral.

Outras ações podem contribuir para o melhor desempenho do trabalhador e menor índice de fadiga relaciona-se ao uso adequado das ferramentas de trabalho em um ritmo único de produção, evitando oscilações na linha; uma melhor postura e adequação de algumas bancadas de trabalho as características antropométricas do trabalhador; e, finalmente como uma ação mais abrangente, a redução da jornada de trabalho do $2^{\mathrm{o}}$ e do $3^{\mathrm{o}}$ turno para 6 horas diárias, uma vez que é a partir desse momento que a fadiga moderada severa tende a acometer os trabalhadores do setor produtivo.

\section{Motivação}

Motivação é o conjunto de fatores psicológicos (conscientes ou inconscientes) de ordem fisiológica, intelectual ou afetiva, os quais agem entre si e determinam a conduta de um indivíduo, despertando sua vontade e interesse para uma tarefa ou ação conjunta.

A motivação não pode ser observada diretamente, mas somente através dos seus efeitos e pode ser medida indiretamente, por exemplo, pelas quantidades adicionais de peças produzidas por um trabalhador motivado. Portanto, um trabalho seria o resultado da habilidade conjugada com a motivação. A habilidade está relacionada com a capacitação ou condições prévias apresentadas pelo trabalhador e a motivação, com a decisão de realizar esse trabalho (RODRIGUES, 1999).

As pessoas são diferentes no que tange à motivação: as necessidades variam de indivíduo para indivíduo, produzindo diferentes padrões de comportamento. A motivação depende, basicamente, de três variáveis: da percepção do estímulo (que varia conforme a pessoa na mesma pessoa, conforme o tempo), das necessidades (que também variam conforme a pessoa) e da cognição de cada pessoa. Ela refere-se ao motivo pelo qual as pessoas fazem as coisas - o porquê de envolverem-se em um dado esforço. A motivação é um processo mais complexo, que não depende da vontade de quem quer motivar, mas da disposição intrínseca daqueles a quem se dirige a estratégia motivacional.

Talvez aqui esteja a principal característica da motivação: ela não é transferível. Uma pessoa altamente motivada não consegue, automaticamente, contagiar aqueles que a rodeiam, por exemplo.

De modo geral, motivo é tudo aquilo que impulsiona a pessoa a agir de determinada forma ou, pelo menos, que dá origem a um comportamento específico. Esse impulso à ação pode ser provocado por um estímulo externo 
(provindo do ambiente) e pode também ser gerado internamente nos processos mentais do indivíduo.

Todo comportamento motivado tem a sua causa determinada por um motivo que, por sua vez, se diferencia dos termos incentivo e impulso. Incentivo é um objeto, condição ou significação externa para o qual o comportamento se dirige, que pode ser positivo, (aquele na direção do qual o comportamento se dirige), e negativo (quando o indivíduo procura afastar-se do comportamento dirigido). Podemos exemplificar o incentivo positivo como sendo o alimento, o dinheiro, o sucesso; e o incentivo negativo como o ferimento, o isolamento social. Impulso é considerado a força que põe o organismo em movimento. É entendido como a consequência de uma necessidade. A fome, por exemplo, é um impulso, consequência da necessidade de alimento. Difere-se do motivo porque não dá direção ao comportamento, é apenas seu ativador. Alguns motivos são considerados não aprendidos, isto é, são aqueles que estão presentes no nascimento ou se desenvolvem por efeito da maturação. É o caso da fome e da sede (RODRIGUES, 1999).

A motivação é considerada como um aspecto intrínseco às pessoas; ninguém pode, por isso mesmo, motivar ninguém, sendo que a motivação específica para o trabalho depende do sentido que se dá a ele. Cabe às organizações encontrar estratégias capazes de desbloquear a saída dos talentos pessoais, para que, objetivamente, se transformem em ações eficazes e produtivas.

Existem muitas teorias na psicologia que procuram explicar a motivação e muitas experiências foram realizadas na tentativa de comprová-las. Elas se dividem basicamente em dois grupos: as teorias de processo e as teorias de conteúdo.

\section{Teorias de processo em motivação}

As teorias de processo preocupam-se em explicar as causas e objetivos do comportamento e determinar as variáveis ou componentes envolvidos nesse processo.

A teoria de processo mais conhecida é a da "expectância-valência". Segundo essa teoria, o comportamento humano dependeria de uma avaliação subjetiva da expectância e da valência de uma tarefa.

A expectância seria uma avaliação subjetiva das chances ou probabilidade de sucesso que uma pessoa faz, antes de iniciar uma tarefa. Isso está relacionado com a quantidade de esforço que seria necessário para se atingir uma meta, como posicionar uma peça corretamente em uma montagem. 
A valência seria o significado do resultado, ganho ou outra consequência da atividade pela qual a pessoa acha que vale a pena realizar essa atividade. A valência seria uma combinação de motivos e recompensas e dependeria da experiência pessoal e da realimentação externa. Geralmente a atividade não tem valor por si só, mas pelas suas consequências como recompensas materiais, ganhos ou reconhecimento social.

Para que uma tarefa seja motivadora, em primeiro lugar, é necessário estabelecer claramente as metas a serem alcançadas. As experiências demonstraram que a fixação de metas ou objetivos concretos é mais motivadora que uma situação em que não se sabe onde se quer chegar. Em segundo lugar, a tarefa é mais motivadora se contiver certo desafio do que aquelas consideradas triviais. Além disso, se o trabalhador tiver informações contínuas ou periódicas dos resultados do seu trabalho, tende a melhorar o seu desempenho, principalmente se esta estiver relacionada com metas concretas a serem atingidas. Essas metas podem ser estabelecidas até mesmo em um trabalho repetitivo, dividindo-se as peças em determinados lotes ou fixando-se certa quantidade a ser processada num tempo determinado.

Em geral, as pessoas também gostam de competir. Assim, o conhecimento dos resultados alcançados por seus colegas funcionam como um desafio, a ser alcançado ou superado, principalmente se houver recompensas para isso.

\section{Teorias de conteúdo em motivação}

As teorias de conteúdo procuram determinar as necessidades que motivam uma pessoa ou a classe de motivos que ela procura atingir. Essas teorias assumem que todas as pessoas têm certas necessidades a serem preenchidas ou certos motivos que direcionam as suas ações. Se uma pessoa tiver várias alternativas para escolher, ela será guiada pelas suas necessidades ou motivos, para escolher uma determinada ação que mais lhe convier. Várias teorias foram levantadas acerca da motivação e do que ela é. Citaremos duas delas:

Teoria de Maslow - as necessidades humanas estão arranjadas em uma pirâmide de importância e de influenciação do comportamento humano. Na base da pirâmide, estariam as necessidades mais baixas e recorrentes, enquanto que no topo estariam as mais sofisticadas e intelectualizadas:

Necessidades pessoais ou fisiológicas constituem o nível mais baixo de todas as necessidades humanas, mas de vital importância. Neste nível estão as necessidades de alimentação (fome e sede), de sono e repouso (cansaço), de abrigo (frio e calor), o desejo sexual, etc. São necessidades que 
já nascem com o próprio indivíduo, contudo estão relacionadas com a sobrevivência e com a preservação da espécie. Quando uma dessas necessidades está insatisfeita (como por exemplo, a fome), o ser humano não pensa em outra coisa. A maior motivação, neste caso, será a necessidade fisiológica, e o comportamento do indivíduo terá a finalidade de encontrar alívio da pressão que essas necessidades produzem sobre o organismo.

As necessidades de segurança constituem o segundo nível das necessidades humanas. São as necessidades de segurança ou de estabilidade, a busca de proteção contra a ameaça ou privação, a fuga ao perigo. Estas têm grande importância no comportamento humano, uma vez que todo o empregado está sempre em relação de dependência com a empresa, na qual as ações administrativas arbitrárias ou decisões incoerentes podem provocar incerteza ou insegurança ao empregado quanto a sua permanência ao emprego.

As necessidades sociais ou de associação surgem no comportamento, quando as necessidades mais baixas (fisiológicas e de segurança) se encontram relativamente satisfeitas. Dentro das necessidades sociais, estão as necessidades de associação, de participação, de aceitação por parte dos companheiros, de troca de amizade, de afeto e amor. Quando essas necessidades não estão satisfeitas, o indivíduo torna-se resistente e hostil em relação às pessoas que o cercam. Em nossa sociedade, a frustração das necessidades de amor e de afeição conduz a falta de adaptação social e a solidão.

As necessidades de estima são os desejos de respeito próprio, sentimento de realização pessoal e de reconhecimento por parte dos outros; estão relacionadas com a maneira pela qual o indivíduo se vê e se avalia. Para satisfazer essas necessidades, as pessoas procuram oportunidades de realização, promoções, prestígio e status para reforçar as suas competências. Contudo, a frustração pode produzir sentimentos de inferioridade, fraqueza, dependência e desamparo que podem levar à sua total desmotivação do ser.

As necessidades de autorrealização pessoal são os desejos de crescimento pessoal e da realização de todos os objetivos pessoais. Uma pessoa que chega a esse nível aceita tanto a si como aos outros. Essas pessoas normalmente exibem naturalidade, iniciativa e habilidade na resolução de 
problemas. Correspondem às necessidades humanas mais elevadas e que estão no topo da hierarquia.

Teoria de Herzberg A investigação de Herzberg demonstrou que os fatores que provocam atitudes positivas face ao trabalho não são os mesmos que provocam as atitudes negativas, ou seja, sugeria que era necessário distinguir os conceitos de motivação e satisfação. Dos dados recolhidos de uma amostra de 203 engenheiros e bancários, resultaram os dezesseis fatores, os quais foram organizados em dois grupos: as necessidades motivadoras e as necessidades higiênicas. Para o autor, esses dois grupos de necessidades orientam o comportamento das pessoas e devem ser considerados independentes e os seus efeitos distinguidos: as necessidades motivadoras e as necessidades higiênicas. As necessidades motivadoras são também chamadas de intrínsecas, pois estão relacionadas com o conteúdo do cargo e com a natureza das tarefas que a pessoa executa. Ao contrário das necessidades higiênicas, as necessidades motivadoras estão sob controle do indivíduo, pois estão relacionados com aquilo que ele faz e desempenha. Envolvem sentimentos de crescimento individual, reconhecimento profissional e autorrealização, e dependem das tarefas que o indivíduo realiza no seu trabalho. O efeito das necessidades motivadoras é profundo, elas provocam satisfação nas pessoas dando origem à motivação, em contrapartida quando são precárias, elas evitam a satisfação. As necessidades higiênicas ou também denominadas extrínsecas se localizam no ambiente que rodeia as pessoas e abrangem as condições dentro das quais elas desempenham seu trabalho. Como essas condições são administradas e decididas pela empresa, as necessidades higiênicas estão fora de controlo das pessoas. As principais necessidades higiênicas são: salário, benefícios sociais, tipo de chefia, condições de trabalho, políticas e diretrizes da empresa, clima de relacionamento entre a empresa e funcionários, regulamentos internos, etc. (Cunha M., 2004)

As pesquisas de Herzberg revelam que as necessidades higiênicas evitam a insatisfação dos empregados e elevam a satisfação dos mesmo conseguindo sustentá-la por muito tempo. Em compensação, quando as necessidades higiênicas são precárias, elas provocam a insatisfação dos empregados.

As necessidades higiênicas são essencialmente preventivas (por isso se chamam higiênicas, ou seja, profiláticas, pois evitam a insatisfação, mas não provocam a satisfação, logo, não conduzem à motivação. 
"A teoria de Herzberg preconiza que a criação de efeitos positivos deve decorrer da mudança do trabalho em si mesmo e não da mudança do ambiente de trabalho, pois estas são de efeito precário; uma outra contribuição desta teoria diz respeito à distinção entre enriquecimento e alargamento da função. Herzberg propõe o enriquecimento de tarefas como elemento para se alcançar a satisfação no cargo. Esse enriquecimento pode ser vertical, aumento do grau de dificuldade do trabalho; ou lateral, diversificação de atribuições. (Teixeira S., 2005)

Para Herzberg, a única forma de fazer com que o indivíduo sentisse vontade própria de realizar a tarefa seria proporcionando-lhe satisfação no trabalho. Noutras palavras, a motivação aconteceria apenas através dos fatores motivadores. O caminho apontado por Herzberg para a motivação é o enriquecimento da tarefa. Por enriquecimento da tarefa entende-se "um deliberado aumento da responsabilidade, da amplitude e do desafio do trabalho"

O enriquecimento da tarefa pode ser conseguido através de formas como:

$\checkmark$ Permitir aos trabalhadores a definição dos seus próprios prazos de execução do trabalho;

$\checkmark$ Permitir-lhes decidir como fazer o trabalho;

$\checkmark$ Permitir-lhes verificar a qualidade do trabalho;

$\checkmark$ Possibilitar-lhes a aquisição de novos conhecimentos; (Cunha M., 2004)

A teoria bifatorial é a mais conhecida, mas é também alvo de algumas críticas:

$\checkmark$ Alguns fatores são híbridos, afetando tanto as atitudes positivas como as atitudes negativas;

$\checkmark$ O papel da remuneração pode ser referida como fonte de atitudes negativas e positivas;

$\checkmark$ Falta de aplicabilidade ao pessoal fabril indiferenciado (Cunha M., 2004)

\section{Importância da motivação}

Um funcionário desmotivado dentro da empresa pode representar um perigo, pois além de não produzir, poderá formar movimentos de contraculturas, podendo ou não influenciar outros funcionários. Caso o gestor não consiga motivar os funcionários a crescerem junto com a empresa, possivelmente seu papel como líder estará sendo ineficiente.

O trabalhador desmotivado inventa desculpa para chegar tarde ou faltar, pois quanto menos tempo no local de trabalho, para ele, melhor se sentirá, uma 
vez que o próprio ambiente não o motiva. Atrelado ao absenteísmo está a acumulação de trabalho por parte do funcionário, haja vista que, a falta de programas de incentivos o deixa desmotivado e lento para a realização das atividades, além de fazê-las de modo "mal feito". Se a empresa deseja que seu funcionário tenha desempenho ótimo, é necessário que ela incentive-o.

Um trabalhador motivado produz mais e melhor. Sofre menos os efeitos da monotonia e da fadiga. Não precisa de muita supervisão, pois procura, por si mesmo, resolver os problemas para alcançar os objetivos.

A motivação não deve ser imposta e sim estimulada, ela surge dentro das pessoas, por essa razão o funcionário tem que querer ser motivado, cabe à empresa oferecer os incentivos necessários para o êxito desse processo motivacional, seja através de promoções ou por meios monetários.

\section{Influências da Idade, sexo e deficiência física.}

No mundo de hoje ainda existem, infelizmente, muitas discriminações e preconceitos ao trabalho de pessoas idosas, mulheres e deficientes físicos.

A ergonomia tem mostrado um crescente interesse no estudo dos mesmos, pois tudo indica que a participação deles na força de trabalho será cada vez maior.

\section{Influência da idade}

Se analisarmos a capacidade de se aprender sobre novas ferramentas de algum trabalho, pilotagem comercial, por exemplo, quem obterá vantagem ou facilidade nessa problemática/oportunidade, alguém mais jovem ou alguém mais idoso? A capacidade de assimilar as novas informações (comandos modernos ou novos equipamentos) certamente será visualizada no nosso candidato jovem, porém, o aprendiz mais idoso logicamente tem horas de voo imensamente superiores as do concorrente, o que lhe facilitará algumas outras assimilações.

Situações como essas serão cada vez mais frequentes nas organizações contemporâneas, sobretudo as futuras. As taxas de natalidade decrescem em muitos países que se desenvolveram industrialmente, aumentando também a expectativa de vida e, consequentemente, a vida útil de trabalho de um indivíduo.

Há nos estudos de ergonomia, dados tabelados trabalhador x serviço que ditam de acordo com as características físicas, a capacidade de se executar com saúde jornadas ou tarefas. Mas quando analisamos indivíduos com idade mais avançada que a usual naquela circunstância, esquece-se um pouco da tabela e faz-se uma análise mais clínica, pois a vitalidade e a fisiologia variam de pessoa 
para pessoa, mesmo que tenham a mesma idade avançada, seria então uma antropometria aplicada individualmente.

Há também outros fatores a se considerar, além das capacidades musculares e mecânicas, tais quais a visão, que diminui gradativamente após os vinte anos, logo no início da maioridade; surgem dificuldades de memória recente, ou então até mesmo confusão em tarefas e a audição também se degrada para sons mais agudos, como o da recepção da fala de um interlocutor.

Contudo, há de se considerar as possibilidades citadas no primeiro exemplo, no início do texto. Apesar de todas essas limitações fisiológicas e psíquicas, a experiência pode prevalecer em alguns casos, aumentando a confiabilidade em determinados processos devido à calma no decorrer dela e também de senilidade, possibilitando a permanência e também a ascensão dos idosos no mercado de trabalho atual e futuro. (Cunha M., 2004)

\section{Influência do sexo}

Cada vez mais as mulheres ocupam espaço no mercado de trabalho, então precisamos somar essas diferenças. Devem-se entender as diferenças e atenuálas, para um melhor entrosamento no trabalho.

A primeira das diferenças existentes entre os sexos tem relação com a própria natureza do sexo masculino e feminino. No geral, o homem tem uma visão mais objetiva e a mulher tem uma visão mais ampla, geral das situações.

Sobre as características das mulheres no trabalho em equipe, elas são mais responsáveis, fiéis e comprometidas. Os homens, por outro lado, cooperam mais.

As diferenças biológicas entre os homens e as mulheres são bem conhecidas: dimensões antropométricas, forças musculares, capacidade cardiovascular e o funcionamento do aparelho reprodutor feminino.

\section{$\checkmark$ Antropometria:}

As mulheres são mais baixas, cerca de $12 \mathrm{~cm}$ em relação aos homens. A falta de adaptação a certos equipamentos, geralmente projetados para uso dos homens, torna o trabalho mais difícil e fatigante para elas.

$\checkmark$ Capacidade Física:

As mulheres têm uma capacidade muscular de aproximadamente dois terços do homem. A capacidade pulmonar também é de $70 \%$ dos homens. O limite para levantamento de peso e carregamento manual, para as mulheres, deve ser fixado em $20 \mathrm{~kg}$ no máximo. Isso não quer dizer que as mulheres sejam menos aptas que os homens, mesmo porque grande parte das tarefas hoje existentes não requerem grandes esforços musculares e o trabalho pode ser planejado de tal 
forma que sejam reservados aos homens aquelas tarefas que exijam maior força física.

$\checkmark$ Capacidade Intelectual:

Não existem diferenças significativas entre homens e mulheres no domínio neuro-sensorial, embora alguns testes de inteligência apresentem alguma vantagem para homens. Contudo, essa pequena diferença se deve à condição social da mulher.

$\checkmark$ Menstruação:

Dois ou três dias antes da menstruação, ocorre uma queda no nível do hormônio progesterona, que provoca irritabilidade, tensão e depressão e até fortes dores. Esse fenômeno é conhecido como tensão pré-menstrual. De acordo com estudos, as mulheres correm mais risco de sofrer lesões musculares e nos tendões por volta da metade e do fim do ciclo menstrual. Entretanto, isso não deve ser usado como argumento para discriminar as mulheres, porque esses sintomas são naturais e fazem parte da natureza feminina.

Além do mais, os homens também sofrem flutuações cíclicas de humor e de disposição para o trabalho, havendo certos dias em que eles ficam mais suscetíveis a erros e acidentes.

A conscientização das diferenças, potenciais e qualidades é uma importante ferramenta para melhorar o trabalho em equipe, a comunicação e a cooperação entre homens e mulheres no trabalho. Homens e mulheres interpretam erradamente uns aos outros de várias maneiras.

Conhecer essas diferenças é uma ferramenta indispensável no campo profissional, pois traz lições de como lidar com a diversidade, solucionar conflitos e melhorar a comunicação entre as pessoas, principalmente aquelas do sexo oposto. Isso também ajuda a manter a equipe de trabalho voltada para a busca de soluções e dirige a atenção de todos para uma meta comum: o sucesso da organização. Homens e mulheres podem se completar no trabalho, cada um executando atividades mais adequadas à sua capacidade física. (Cunha M., 2004)

\section{Influência da deficiência física}

Deficientes físicos são aquelas pessoas que não podem exercer plenamente as suas aptidões físicas, em consequência de doenças ou acidentes. Cada deficiente apresenta um quadro próprio de deficiência, que, em geral, pode ser classificado em:

$\checkmark$ Os que dependem permanentemente da cadeira de rodas.

$\checkmark$ Os que usam pernas mecânicas, muletas ou bengalas.

$\checkmark$ Os que são parcial ou completamente cegos. 
$\checkmark$ Os que são parcial ou completamente surdos.

$\checkmark$ Os que têm lesões no sistema nervoso central

$\checkmark$ As diversas deficiências provocadas pela idade avançada

Muitos esforços são feitos no sentido de integrá-los melhor à sociedade, capacitá-los para o trabalho.

Análise da deficiência - $\mathrm{O}$ deficiente físico não pode ser comparado simplesmente a uma pessoa normal, do qual se subtraiu alguma habilidade. De certa forma, há um mecanismo de compensação. Os surdos podem ter aguçada a sua percepção visual, e os cegos desenvolvem capacidade de concentrar-se nas sensações táteis, auditivas e sinestésicas. Os paralíticos desenvolvem força e habilidade com as mãos e aqueles que não têm mãos podem substituí-las, pelo menos parcialmente, pelo desenvolvimento de uma maior mobilidade dos pés. Em cada caso, as deficiências deverão ser objeto de exame médico cuidadoso, para se recomendar as técnicas de reabilitação adequadas.

Deficientes físicos na indústria - Muitas indústrias já promovem o aproveitamento de deficientes físicos. Mediante escolha adequada da tarefa, treinamento e adaptação dos postos de trabalho, os deficientes podem tornar-se tão produtivos quanto às pessoas normais. Da mesma forma que existem os automóveis para paraplégicos, com todos os controles manuais ( sem os pedais), na indústria também podem ser feitas adaptações semelhantes nas máquinas.

O principal aspecto que deve ser analisado nas relações de trabalho que envolve trabalhadores portadores de deficiência física é preceito constitucional: a dignidade da pessoa humana. Há uma vasta quantidade de normas, sejam estas na esfera federal, municipal ou estadual que visam proteger o portador de deficiência física nas relações de trabalho, objetivando a efetiva integração social.

A Lei no $7.853 / 1989$ estabelece que a empresa com 100 ou mais empregados está obrigada a preencher de $2 \%$ a $5 \%$ de seus cargos com beneficiários da previdência Social reabilitados ou com pessoas portadoras de deficiência habilitadas, na seguinte proporção:

I - até 200 empregados: 2\%;

II - de 201 a 500 empregados: 3\%;

III - de 501 a 1000: 4\%;

IV - mais de 1000 empregados: 5\%.

$\checkmark$ Os deficientes estão conseguindo cada vez mais superar o isolamento e participar da atividade produtiva e da vida social. (Cunha M., 2004)

\section{Considerações Finais}


Diante disso, verifica-se a importância do Enfermeiro do Trabalho junto ao trabalhador para identificar os possíveis sinais de agravos à saúde, decorrentes da jornada de trabalho para que assim possa haver uma mudança na forma de pensamento dos empregadores, dando ênfase no ditado "prevenir é melhor que remediar", também se aplica às organizações na melhoria da qualidade de vida dos trabalhadores. Quanto maior o investimento em qualidade de vida, maior será o retorno em termos de produtividade, qualidade e financeiramente para o empregador tendo assim influência na qualidade de vida do trabalhador.

As instituições devem implementar em suas rotinas programas que visem à melhoria da qualidade de vida, reduzindo assim o estresse e as pressões decorrentes do trabalho e, em consequência, as morbidades que podem afetar o trabalhador, melhorando a satisfação profissional e o envolvimento do profissional com o serviço e com a empresa.

O enfermeiro do trabalho tem suma importância nesse processo em que deve se ter uma visão holística pra o trabalhador e o ambiente de trabalho.

\section{Referências}

CANETE, I. Humanização: desafio da empresa moderna; a ginástica laboral como um caminho. Porto Alegre; Artes e Ofícios, 1996.

COUTO, H.de A. Ergonomia aplicada ao trabalho: Manual técnico da Máquina Humana- Belo Horizonte: Ergo Editora, 1995.

CUNHA M.; REGO, A.; CUNHA, R.; CARDOSO, C. Manual de comportamento organizacional e gestão, Editora RH, 3.ed., 2004, pp. 103-119.)

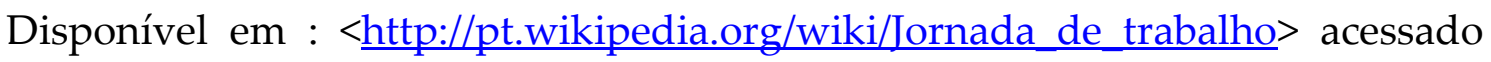
em 20 de janeiro de 2012).

FILHO I. G. R. Síndrome da má-adaptação ao trabalho em turnos - uma abordagem ergonômica. Revista Produção, v. 11 n. 2, abril de 2002.

GRANDJEAN, E. Manual de Ergonomia: adaptando o trabalho ao homem. Porto Alegre: Artes Médicas, 1998. 
LOURENÇÃO, L. G.; MOSCARDINI, A. C.; SOLER, Z. A. S. G. Saúde e qualidade de vida de médicos residentes. Revista da Associação Médica Brasileira, 2010. n. 56, v. 1, 81-91.

NERY, D.; TOLEDO, A. M.; OLIVEIRA JÚNIOR, S.; TACIRO, C.; CARREGARO, R. Análise de parâmetros funcionais relacionados aos fatores de risco ocupacionais da atividade de enfermeiros de UTI. Fisioter Pesq. 2013;20(1):7682.

PEREIRA, C. C. D. A. Efeitos de um programa de ginástica laboral sobre as principais sintomatologias das lesões por esforços repetitivos /distúrbios osteo - musculares relacionados ao trabalho. (LER/DORT): Dor e fadiga. Dissertação (Mestrado), UNB, Brasília, 2009.

OIT - Escritório da Organização Internacional do Trabalho. Perfil do trabalho decente no Brasil, $2009 . \quad$ Disponível em http://www.oitbrasil.org.br/sites/default/files/topic/decent work/pub/perfil do trabalho decente 301.pdf.( Acessado em 20 de janeiro de 2012).

RODRIGUES, L. S. O engajamento organizacional dos indivíduos na perspectiva da gestão estratégica do conhecimento. 1999. Dissertação (Mestrado em Engenharia da Produção - Área de Concentração: Ergonomia) Universidade Federal de Santa Catarina, Santa Catarina - SC.

TEIXEIRA, S. Gestão das Organizações. McGrawHill, 2005, pp. 140-154. 